\title{
Physician Orders for Life Sustaining Treatment for \\ Nursing Home Residents with Dementia
}

Hyejin Kim, MSN, CRNP'; Mary Ersek, PhD, RN, FAAN ${ }^{1,2}$; Christine Bradway, PhD, CRNP,

FAAN ${ }^{1}$; Susan E. Hickman, $\mathrm{PhD}^{3}$

${ }^{1}$ University of Pennsylvania School of Nursing, Philadelphia, PA
${ }^{2}$ Philadelphia VAMC, Philadelphia, PA
${ }^{3}$ Indiana University School of Nursing, Indianapolis, IN

Corresponding author: Hyejin Kim, MSN, CRNP

University of Pennsylvania School of Nursing

Claire M. Fagin Hall, 418 Curie Boulevard

Philadelphia, PA 19104, USA

Email: hyejin@nursing.upenn.edu

This is the author's manuscript of the article published in final edited form as:

Kim, H., Ersek, M., Bradway, C., \& Hickman, S. E. (2015). Physician Orders for Life-Sustaining Treatment for nursing home residents with dementia. Journal of the American Association of Nurse Practitioners. http://dx.doi.org/10.1002/2327-6924.12258 


\begin{abstract}
Purpose: Many nursing home (NH) residents with dementia receive burdensome, aggressive treatments at the end-of-life (EOL). The Physician Orders for Life-Sustaining Treatments (POLST) paradigm is a strategy to enhance EOL care. This article describes the history and features of the POLST paradigm, discusses the potential advantages of using this paradigm for NH residents with dementia, and briefly explores challenges that nurse practitioners face in using the POLST for persons with dementia.
\end{abstract}

Data Sources: Review of the literature

Conclusions: Potential advantages associated with implementation of POLST in NH residents with dementia include increased communication and documentation about residents' EOL care preferences, increased concordance between care preferences documented in POLST forms and EOL care provided to residents, and lower rates of unwanted, burdensome treatments at EOL. POLST may also guide nurse practitioners in communicating EOL care options with residents and/or their surrogates. However, difficulty interpreting and explaining POLST care options, lack of understanding of POLST, limited discussions, and issues with surrogate authority and scope of practice are challenges that nurse practitioners may face in caring for NH residents with dementia.

Implications for Practice: Nurse practitioners should assess and optimize their knowledge and skills to conduct goals of care discussions, including POLST discussions.

Keywords: Physician Orders for Life-Sustaining Treatments, nurse practitioners, nursing homes, dementia, surrogates, palliative care, decision-making 


\section{Goals of Care Discussions and Advance Directives for Persons with Dementia}

Dementia is a progressive, terminal illness that currently afflicts more than five million Americans (Alzheimer's Association, 2012) and is the fifth leading cause of death of older Americans (Minino, 2011). Approximately 50 percent of persons with dementia die in nursing homes (NHs) (Teno et al., 2013). For NH residents with dementia, infections (i.e., pneumonia), febrile episodes, eating problems, uncontrolled pain, and dyspnea are common (Mitchell, Kiely, \& Hamel, 2004; Mitchell et al., 2009). Moreover, these issues often lead to burdensome transitions to hospitals and emergency rooms, feeding-tube insertion, and use of intravenous antibiotics and fluids (Gozalo et al., 2011; Mitchell et al., 2009). In addition, symptom assessment and management often is inadequate (Black et al., 2006; Mitchell et al., 2004).

One way to enhance end-of-life (EOL) care and outcomes is to engage in discussions about goals of care. The purposes of these conversations are to: 1) elicit patients' and families' values and preferences related to their health and healthcare; 2) establish their understanding of the illness and its trajectory; 3) present the full range of treatment options, and 4) answer questions they may have. However, several studies found that goals-of-care discussions between healthcare providers and persons with dementia/ their surrogates are uncommon (Garand, Dew, Lingler, \& DeKosky, 2011; Godwin \& Waters, 2009). Barriers to conducting these conversations include: 1) avoidance of conversations about EOL; 2) inappropriate timing of conversations; 3) prognostic uncertainty; 4) inadequate knowledge and training; and 5) emotional burden that is associated with these discussions (Dening, Jones, \& Sampson, 2011; Hirschman, Kapo, \& Karlawish, 2008; Robinson et al., 2013).

One of the outcomes of goals-of-care conversations is the completion of an advance directive. Advance directives are completed by competent adults and are activated when the 
person is no longer able to make and communicate their own decisions. The right of adults to complete advance directives was formalized in the wake of several precedent-setting court cases, and culminated in the Patient Self-Determination Act of 1990 (Bomba \& Vermilyea, 2006). These legal documents may either be a living will, in which a person declares their preferences for specific treatment, or a durable power of attorney for healthcare (DPOA-HC) that designates the person's choice to be their surrogate decision maker. All states recognize the right of an adult with capacity to appoint a pre-identified decision-maker to speak on his or her behalf. This designee is termed "Health Care Proxy," "Health Care Agent," "Medical/Health Care Power of Attorney" among other titles. In cases where a person does not explicitly designate a healthcare decision-maker, decisions may be made by a default surrogate. Over 75 percent of states have laws that identify default surrogates (see Table 1).

Despite the promise of advance directives, they are not panaceas (Fagerlin \& Schneider, 2004). Advance directive frequently are completed without conversations with healthcare providers, which may contribute to the person's misunderstanding of EOL treatments (Fagerlin \& Schneider, 2004). Moreover, decisions that are made while one is healthy may not accurately predict the decisions one would make during serious illness (Fagerlin \& Schneider, 2004). In addition, living wills are often too vague to guide healthcare providers and surrogates in making decisions in specific clinical circumstances (Black et al., 2009; Triplett et al., 2008). Surrogate decision makers are responsible for specifying the wishes of a person who is not capable of making or communicating their preferences for care. However, they do not always know what treatment the incapacitated person would want because they have not discussed the person's goals of care. Another shortcoming of advance directives is that they are not always accessible when decisions need to be made (Fagerlin \& Schneider, 2004). Finally, advance directives may 
not affect the care received. Silveira et al. (2014) reported that although the percentage of older adults who advance directives increased over a decade, this increase is not associated with lower hospitalization rates at the EOL. The Physician Orders for Life-Sustaining Treatment (POLST) paradigm seeks to address these limitations (Hickman, Hammes, Tolle, \& Moss, 2004).

Nurse practitioners (NPs) practicing in NHs provide residents with acute and chronic care; educate residents, families, and NH staff; and consult with staff regarding NH care issues (Bakerjian, 2008). NP-led care models are associated with better quality of care and outcomes compared with non-NP practice. These outcomes include fewer transitions to hospitals; reduced care costs; improved communication with residents and family members; increased advance directive completion; and improved resident, family, and staff satisfaction (Bakerjian, 2008; Ersek et al., 2013; Teno et al., 2013; Teno et al., 2011). However, literature regarding NPs’ involvement in goals-of-care discussions in NHs, particularly POLST discussions and completion, is sparse. Moreover, little research has been focused on POLST use in individuals with dementia. Therefore, this article: 1) describes the history and features of the POLST paradigm; 2) discusses the potential advantages of using this paradigm for NH residents with dementia; and 3) explores challenges that NPs may face in using POLST for persons with dementia.

\section{The POLST Paradigm}

The POLST paradigm is an approach to planning EOL care that is based on shared decision making through goals-of-care discussions between healthcare providers, patients, and their surrogates. The goal is to ensure that patients and surrogates explore and communicate their preferences for EOL care. The outcome of these discussions may be the completion of a form in which preferences are translated directly into actionable medical orders. Thus, a completed, 
signed POLST is not an advance directive, but rather is a medical order (National POLST, 2012).

The POLST paradigm started in Oregon in 1991. Since that time, it has expanded to a national program. Currently, 43 states have POLST programs, either in development or fully endorsed. Depending on the state, POLST also is referred to as Medical Orders for LifeSustaining Treatment (MOLST), Medical Orders for Scope of Treatment (MOST), and Physician Orders for Scope of Treatment (POST) (National POLST, 2012). The documentation form for POLST also varies across the United States. However, most are printed on a brightly-colored paper and consist of three to four treatment sections. These sections cover cardiopulmonary resuscitation, medical interventions (comfort measures, limited interventions, or full treatment), artificially administered nutrition, and/or antibiotics. Figure 1 is an example of a state-specific POLST from Pennsylvania.

POLST is different from advance directives (Bomba, Kemp, \& Black, 2012 -- see Table 2). Advance directives may be completed by any adult who is capable of making informed decisions about future care. In contrast, POLST is prepared by healthcare providers through discussions with seriously ill or frail patients or their surrogates (Bomba, Kemp, \& Black, 2012). POLST may more effectively reflect changes in patients’ treatment preferences as diseases progress. For NH residents with dementia, the form is often completed or updated through discussions between healthcare providers and surrogates in most states. Surrogates are able to choose treatment options that seem to be the best for the current health status of individuals with dementia.

As a medical order POLST becomes actionable immediately after it is signed by a physician, NP, or physician assistant. In most states, the form also requires a patient's and/or 
surrogate's signature (ABA Commission on Law Aging, 2014). Another feature of the POLST is its transferability across care settings, which enables healthcare personnel to promote appropriate, timely care for persons with serious illnesses in emergencies (National POLST, 2012). A completed POLST is recognized throughout the healthcare system in a state, thus helping seriously ill or frail individuals receive continuous care across care settings.

POLST does not replace advance directives or other medical orders; rather, POLST and advance directives complement each other. For example, in most states, persons named as a DPOA-HC can participate in POLST discussions and sign the POLST on behalf of their loved ones who lack decisional capacity (Bomba et al., 2012). Thus, having a legally authorized agent appointed in advance directives facilitates the POLST process.

Use of POLST in NHs varies nationwide. In Oregon, where the POLST program is mature, nearly 70 percent of NHs used POLST (Hickman, Tolle, Brummel-Smith, \& Carley, 2004). In contrast, 40 percent of 115 Pennsylvania NHs that responded to a survey in 2012 reported that they used the POLST (Aging Institute of UPMC Senior Services and the University of Pittsburgh, 2014).

\section{Outcomes Associated with POLST}

Several studies have documented improved EOL care and other outcomes associated with the POLST paradigm. Patients with POLST documentation have an increased prevalence of specified medical orders regarding EOL care (Hammes, Rooney, \& Gundrum, 2010; Hickman et al., 2010; Hickman, Tolle, et al., 2004). One study examining POLST use in NHs found 98 percent of NH residents who completed POLST had standing orders regarding medical interventions, antibiotics, or artificial nutrition and hydration, whereas only 16 percent of those without POLST documentation had similar directions specified (Hickman et al., 2010). In 
addition, care preferences regarding hospitalization were stated for 97 percent of NH residents with POLST documentation versus 14 percent of those without POLST documentation (Hickman et al., 2010). Interestingly, 8 in 10 POLST forms indicating do-not-resuscitate (DNR) orders included orders for more than "comfort measures only,” (e.g., antibiotics, or artificial nutrition and hydration). Thus, DNR orders should not be interpreted as preferences for no lifesustaining treatment (Hickman, Tolle, et al., 2004).

In addition to being more likely to have specific medical orders regarding life-sustaining therapies, POLST improves congruence between patients’ preferences for care and the medical treatments that patients receive (Araw et al., 2013; Fromme, Zive, Schmidt, Cook, \& Tolle, 2014; Hammes et al., 2010; Hickman et al., 2011; Hickman et al., 2010; Richardson, Fromme, Zive, Fu, and Newgard, 2013; Tolle, Tilden, Nelson, \& Dunn, 1998). For example, in a study measuring consistency between orders stated in POLST and care provided to decedents in NHs in Oregon, the overall congruence rate was 94 percent (Hickman et al., 2011). Richardson, Fromme, Zive, Fu, and Newgard (2013) reported that POLST documentation was associated with high concordance between care preferences and care provided to patients experiencing outof-hospital and emergency room cardiopulmonary arrest. In another study, 66 percent of decedents in Oregon had a "comfort care only” order in their POLST documents and about 6 percent of those died in hospitals, which suggests that their preferences for avoiding aggressive therapies and hospitalization were honored by healthcare providers (Fromme, Zive, Schmidt, Cook, \& Tolle, 2014).

The majority of POLST forms indicate patients’ preferences for less aggressive treatments. Hickman, Tolle, et al. (2004) found that almost 9 in 10 POLST forms contained DNR orders and a limited use of aggressive interventions and feeding tubes. In another study, about 90 
percent of POLST included orders for no hospitalization unless comfort could not be achieved in NHs (Araw et al., 2013). Thus, use of POLST is associated with lower use of unwanted lifesustaining treatments (Araw et al., 2013; Hammes, Rooney, Gundrum, Hickman, \& Hager, 2012; Hickman et al., 2010; Hickman, Tolle, et al., 2004).

Finally, the POLST form serves as a structured framework for goals-of-care discussions between healthcare providers and surrogates of NH residents (Caprio, Rollins, \& Roberts, 2012; Hickman et al., 2009; Hickman, Tolle, et al., 2004). In a 3-state study, almost all hospice staff participants considered POLST a useful tool for initiating discussions about EOL-care preferences (Hickman et al., 2009).

Based on these positive outcomes, the POLST may be a useful tool for NH residents with dementia. Fifty percent of adults with dementia die in NHs and 70 percent of NH residents with advanced dementia die within six months of NH admission (Mitchell et al., 2004; Teno et al., 2013); however, a large percent of this specific population do not have specific medical orders regarding their EOL care until their death is imminent (Lamberg, Person, Kiely, \& Mitchell, 2005; Vandervoort et al., 2012). In addition, common EOL decisions for persons with dementia involve discussions of feeding options and hospitalization. Difficulty with eating occurs in over 80 percent of NH residents with advanced dementia (Mitchell et al., 2009), and may lead to feeding tube placement, a medical therapy with no documented benefits in this population (American Geriatrics Society, 2013; Kuo, Rhodes, Mitchell, Mor, \& Teno, 2009). Moreover, burdensome transitions, defined as “any transfer in the last 3 days of life,” “a lack of continuity of nursing home facilities before and after a hospitalization in the last 90 days of life,” and “multiple hospitalizations in the last 90 days of life,” (p. 2) occur in 20 percent of NH residents with advanced cognitive impairment (Gozalo et al., 2011). Despite the potential benefits, POLST 
use in persons with dementia has received little attention in the research literature. We could identify no studies that specifically address this issue, although Hickman et al. reported that presence of a POLST among residents of 90 nursing facilities across 3 states was not associated with cognitive status (Hickman et al., 2010).

\section{Challenges in Implementing the POLST}

Several studies identified specific challenges about healthcare providers’ implementation of POLST. These include lack of knowledge and skills about the POLST paradigm and limited discussions between healthcare providers, residents, and surrogates (Caprio et al., 2012; Hickman et al., 2009; Hickman, Nelson, Smith-Howell, \& Hammes, 2014; Meyers, Moore, McGrory, Sparr, \& Ahern, 2004; Vo et al., 2011; Wenger et al., 2013). Healthcare providers often report difficulty interpreting and explaining POLST care options (Hickman et al., 2009; Wenger et al., 2013), specifically those therapies that are covered in Section B (Figure 1). In Caprio et al.’s study, physicians, NPs and social workers reported that this section was the most challenging to interpret and explain to residents and surrogates (Caprio et al., 2012). The investigators also found that clinicians describe these options using varying language, with potentially different interpretations. For example, “full treatment” was explained as “doing everything possible” or "usual medical care.” Other providers described that they discussed full treatment only in the context of decisions about cardiopulmonary resuscitation (Caprio et al., 2012). Similarly, some healthcare providers believed that comfort measures were appropriate only for dying persons (Caprio et al., 2012), a misconception that can affect patients’ and surrogates’ choices.

These discrepancies in practice reflect a need for educating NH providers. Sabatino and Karp (2011) assert that education should focus on developing communication skills to facilitate 
decision-making discussions and increased knowledge about the risks and benefits of lifesustaining therapies in seriously ill, older adults. However, their report documented that lack of funding and resources for training programs are significant barriers to implementing POLST. They also found that research that evaluates the effectiveness of POLST training on the quality of conversations and care is scarce.

Another challenge in implementing POLST for persons with advanced dementia is that treatment decisions frequently are made by surrogates, often with little specific input from the persons with dementia (Maust, Blass, Black, \& Rabins, 2008; Mitchell, Berkowitz, Lawson, \& Lipsitz, 2000). Also, treatment discussions between physicians or NPs and surrogates of NH residents are uncommon (Meyers et al., 2004; Wenger et al., 2013), even though surrogates report being more supported and satisfied when providers communicate with them(Givens, Kiely, Carey, \& Mitchell, 2009).

POLST implementation also is hindered by differences in surrogates’ authority in EOLdecision making among states. Some states limit the types of treatment decisions that surrogates can make. For example, at present surrogates in Oklahoma may not decide on behalf of the patient to forego artificial nutrition and hydration unless one of five conditions exist (e.g., the patient has a legal advance directive authorizing forgoing of the therapy) (Hickman, Sabatino, Moss, \& Nester, 2008).

In addition to the challenges identified above, the scope of NP practice related to POLST differs across the states. In most states, non-physician providers, including NPs, may facilitate POLST discussions and prepare the document (Bomba et al., 2012). However, some states currently do not allow NPs to sign off on POLST orders (ABA Commission on Law Aging, 2014). NPs must keep up-to-date with regards to their authority to sign POLST orders in the 
state(s) where they practice (www.polst.org/programs-in-your-state/) and to advocate for expanded authority in states that limit their ability to engage fully in the POLST process.

\section{Implications for Practice}

NPs provide extensive education to residents and their families and generally spend more time overall with residents than physicians (Bakerjian, 2008). The NP role requires strong communication skills and the ability to facilitate discussions about goals of care and treatment options with residents and families (American Association of Colleges of Nursing, 2010). There is some evidence for the positive effect of NPs' skills on better EOL care and improved decisionmaking. For example, NP and physician assistant presence in nursing homes is associated with decreased terminal hospitalizations (Teno et al., 2011) and increased prevalence of surrogateprovider discussions about feeding tubes (Ersek et al., 2013). For these reasons, NPs are well poised to promote discussion about choices and completion of POLST forms.

Although no rigorous studies of NP involvement in POLST implementation were found in the literature, Hartle, Thimons and Angelelli conducted a pilot study in which one NP was assigned to attend care planning meeting for NH residents with POLSTs and to discuss POLST preferences with residents or their surrogates. (Hartle, Thimons, \& Angelelli, 2014). As a result, 14 out of 60 residents had POLST documents updated to reflect preferences for less-aggressive life-sustaining treatments (Hartle et al., 2014). Despite methodological limitations, this study highlights the importance of NP's contribution to routine care planning by discussing POLST with $\mathrm{NH}$ residents or surrogates.

Specific education about POLST conversations may increase NPs' effectiveness in eliciting treatment preferences. One approach identifies an eight-step protocol that integrates POLST into the advance care planning discussion (Bomba \& Vermilyea, 2006; Bomba, Kemp, 
\& Black, 2012 - see Table 3). A clearinghouse of POLST educational resources are available on the National POLST Paradigm Task Force website at http://www.polst.org/ (National POLST, 2012). These resources provide informative webinars, presentations, and research regarding the POLST paradigm that may be useful for NPs who are not familiar with the POLST paradigm. An alternative model is the Respecting Choices ${ }^{\circledR}$ Last Steps POLST Facilitation model, which is a licensed training program owned and operated by Gunderson Health System in La Crosse, Wisconsin (Briggs, 2014; Gundersen Health System, 2014). The Last Steps ${ }^{\circledR}$ facilitator training is designed to help participants learn the skills to conduct EOL discussions with frail elders, often those living in long-term care facilities. Didactic content is presented on-line with follow-up face-to-face training and practice. After successful completion of all components, participants are certified as facilitators in the Respecting Choices- Last Steps ${ }^{\circledR}$ method. Although this model is evidence-based and standardized, certification requires time and financial resources that are not always available.

Additionally, NPs may participate in research regarding the POLST implementation to help healthcare organizations develop POLST-related, evidence-based quality standards or measures. Currently, there is a lack of quality standards or measures regarding the POLST process, which may impede adequately evaluating POLST-related outcomes (Sabatino \& Karp, 2011). Furthermore, it is important for NPs to pay attention to and give their voices for changes in healthcare policies/regulations and payment systems regarding advance care planning including POLST.

\section{Conclusion}

The POLST paradigm is a strategy to improve EOL care in NH residents with dementia. This paradigm encourages goals-of-care discussions and shared decision making between 
healthcare providers and residents or their surrogates, and ensures that care decisions are honored by healthcare providers across care settings. Additional research is needed to identify the most effective ways to conduct POLST discussions and to integrate this practice into usual NH care. In addition, understanding the perspective of surrogates and the most effective methods to involve surrogates in the process - that is, strategies that result in POLST orders that truly honor the residents' values and preferences - is critical. To date, these perspectives and strategies are not clearly identified. NPs providing care for frail NH residents, including those with dementia, are in an ideal position to enhance both the evidence and the practice of the POLST paradigm. Thus, NPs need to improve their skills to discuss POLST with residents or surrogates and increase knowledge regarding the POLST paradigm. The roles of NPs in the POLST process also need to be clarified. 


\section{References}

ABA Commission on Law Aging. (2014, January 1, 2014). POLST program legislative comparison. Retrieved June 7, 2014, from http://www.americanbar.org/content/dam/aba/administrative/law_aging/2014_POLST_L eg_Chart_Dec_2014_3-column.authcheckdam.pdf

Aging Institute of UPMC Senior Services and the University of Pittsburgh. (2014). Pennsylvania POLST (Pennsylvania Orders for Life Sustaining Treatment). Retrieved April 1, 2014, from http://www.upmc.com/services/aginginstitute/partnerships-andcollaborations/pages/polst.aspx

Alzheimer's Association. (2012). 2012 Alzheimer's disease facts and figures. Retrieved November 1, 2012, from http://www.alz.org/downloads/facts_figures_2012.pdf American Association of Colleges of Nursing. (2010). Adult-Gerontology primary care nurse practitioner competencies. Retrieved July 6, 2014, from http://www.aacn.nche.edu/geriatric-nursing/adultgeroprimcareNPcomp.pdf

Araw, A. C., Araw, A. M., Pekmezaris, R., Nouryan, C. N., Sison, C., Tommasulo, B., \& WolfKlein, G. P. (2013). Medical orders for life-sustaining Treatment: Is it time yet? Palliative \& Supportive Care, 1-5. doi: 10.1017/s1478951512001010

Bakerjian, D. (2008). Care of nursing home residents by advanced practice nurses. A review of the literature. Research in Gerontological Nursing, 1(3), 177-185. doi: 10.3928/00220124-20091301-01

Black, B. S., Finucane, T., Baker, A., Loreck, D., Blass, D., Fogarty, L., . . Rabins, P. V. (2006). Health problems and correlates of pain in nursing home residents with advanced 
dementia. Alzheimer Disease and Associated Disorders, 20(4), 283-290. doi:

10.1097/01.wad.0000213854.04861.cc

Black, B. S., Fogarty, L. A., Phillips, H., Finucane, T., Loreck, D. J., Baker, A., . . Rabins, P. V. (2009). Surrogate decision makers' understanding of dementia patients' prior wishes for end-of-life care. Journal of aging and health, 21(4), 627-650.

Bomba, P. A., Kemp, M., \& Black, J. S. (2012). POLST: An improvement over traditional advance directives. Cleveland Clinic Journal of Medicine, 79(7), 457-464. doi: 10.3949/ccjm.79a.11098

Bomba, P. A., \& Vermilyea, D. (2006). Integrating POLST into palliative care guidelines: a paradigm shift in advance care planning in oncology. Journal of the National Comprehensive Cancer Network, 4(8), 819-829.

Briggs, L. A. (2014). Respecting Choices: An evidence-based advance care planning program with proven success and replication. In L. Rogne \& S. L. McCune (Eds.), Advance care planning: Communicating about matters of life and death (pp. 223-242). New York, NY Springer Publishing Company, LLC.

Caprio, A. J., Rollins, V. P., \& Roberts, E. (2012). Health care professionals' perceptions and use of the medical orders for scope of treatment (MOST) form in North Carolina nursing homes. Journal of the American Medical Directors Association, 13(2), 162-168. doi: 10.1016/j.jamda.2010.07.006

Dening, K. H., Jones, L., \& Sampson, E. L. (2011). Advance care planning for people with dementia: a review. International Psychogeriatrics, 23(10), 1535-1551. doi: 10.1017/S1041610211001608 
Ersek, M., Sefcik, J. S., Lin, F. C., Lee, T. J., Gilliam, R., \& Hanson, L. C. (2013). Provider Staffing Effect on a Decision Aid Intervention. Clinical Nursing Research. doi: $10.1177 / 1054773812470840$

Fagerlin, A., \& Schneider, C. E. (2004). Enough. The failure of the living will. The Hastings Center Report, 34(2), 30-42.

Fromme, E. K., Zive, D., Schmidt, T. A., Cook, J. N., \& Tolle, S. W. (2014). Association Between Physician Orders for Life-Sustaining Treatment for Scope of Treatment and InHospital Death in Oregon. J Am Geriatr Soc. doi: 10.1111/jgs.12889

Givens, J. L., Kiely, D. K., Carey, K., \& Mitchell, S. L. (2009). Healthcare proxies of nursing home residents with advanced dementia: decisions they confront and their satisfaction with decision-making. Journal of the American Geriatrics Society, 57(7), 1149-1155. doi: 10.1111/j.1532-5415.2009.02304.x

Gozalo, P., Teno, J. M., Mitchell, S. L., Skinner, J., Bynum, J., Tyler, D., \& Mor, V. (2011). End-of-life transitions among nursing home residents with cognitive issues. The New England Journal of Medicine, 365(13), 1212-1221. doi: 10.1056/NEJMsa1100347

Gundersen Health System. (2014). Respecting Choices: Advance care planning. Retrieved April 1, 2014, from http://www.gundersenhealth.org/respecting-choices

Hammes, B. J., Rooney, B. L., \& Gundrum, J. D. (2010). A comparative, retrospective, observational study of the prevalence, availability, and specificity of advance care plans in a county that implemented an advance care planning microsystem. Journal of the American Geriatrics Society, 58(7), 1249-1255. doi: 10.1111/j.1532-5415.2010.02956.x

Hammes, B. J., Rooney, B. L., Gundrum, J. D., Hickman, S. E., \& Hager, N. (2012). The POLST program: a retrospective review of the demographics of use and outcomes in one 
community where advance directives are prevalent. Journal of Palliative Medicine, 15(1), 77-85. doi: 10.1089/jpm.2011.0178

Hartle, G. A., Thimons, D. G., \& Angelelli, J. (2014). Physician Orders for Life Sustaining Treatment in US Nursing Homes: A Case Study of CRNP Engagement in the Care Planning Process. Nursing Research and Practice, 2014, 761784. doi:

\section{$10.1155 / 2014 / 761784$}

Hickman, S. E., Hammes, B. J., Tolle, S. W., \& Moss, A. H. (2004). A viable alternative to traditional living wills. The Hastings Center Report, 34(5), 4-5; author reply 5-6.

Hickman, S. E., Nelson, C. A., Moss, A. H., Hammes, B. J., Terwilliger, A., Jackson, A., \& Tolle, S. W. (2009). Use of the Physician Orders for Life-Sustaining Treatment (POLST) paradigm program in the hospice setting. Journal of Palliative Medicine, 12(2), 133-141. doi: 10.1089/jpm.2008.0196

Hickman, S. E., Nelson, C. A., Moss, A. H., Tolle, S. W., Perrin, N. A., \& Hammes, B. J. (2011). The consistency between treatments provided to nursing facility residents and orders on the physician orders for life-sustaining treatment form. Journal of the American Geriatrics Society, 59(11), 2091-2099. doi: 10.1111/j.1532-5415.2011.03656.x

Hickman, S. E., Nelson, C. A., Perrin, N. A., Moss, A. H., Hammes, B. J., \& Tolle, S. W. (2010). A comparison of methods to communicate treatment preferences in nursing facilities: traditional practices versus the physician orders for life-sustaining treatment program. Journal of the American Geriatrics Society, 58(7), 1241-1248. doi: 10.1111/j.15325415.2010.02955.x 
Hickman, S. E., Nelson, C. A., Smith-Howell, E., \& Hammes, B. J. (2014). Use of the physician orders for life-sustaining treatment program for patients being discharged from the hospital to the nursing facility. Journal of Palliative Medicine, 17(1), 43-49.

Hickman, S. E., Sabatino, C. P., Moss, A. H., \& Nester, J. W. (2008). The POLST (Physician Orders for Life-Sustaining Treatment) paradigm to improve end-of-life care: potential state legal barriers to implementation. The Journal of Law, Medicine \& Ethics, 36(1), 119-140, 114. doi: 10.1111/j.1748-720X.2008.00242.X

Hickman, S. E., Tolle, S. W., Brummel-Smith, K., \& Carley, M. M. (2004). Use of the Physician Orders for Life-Sustaining Treatment program in Oregon nursing facilities: beyond resuscitation status. Journal of the American Geriatrics Society, 52(9), 1424-1429. doi: 10.1111/j.1532-5415.2004.52402.x

Hirschman, K. B., Kapo, J. M., \& Karlawish, J. H. (2008). Identifying the factors that facilitate or hinder advance planning by persons with dementia. Alzheimer Disease and Associated Disorders, 22(3), 293-298. doi: 10.1097/WAD.0b013e318169d669

Kuo, S., Rhodes, R. L., Mitchell, S. L., Mor, V., \& Teno, J. M. (2009). Natural history of feeding-tube use in nursing home residents with advanced dementia. Journal of the American Medical Directors Association, 10(4), 264-270. doi:

10.1016/j.jamda.2008.10.010

Lamberg, J. L., Person, C. J., Kiely, D. K., \& Mitchell, S. L. (2005). Decisions to hospitalize nursing home residents dying with advanced dementia. Journal of the American Geriatric Society, 53(8), 1396-1401.

Maust, D. T., Blass, D. M., Black, B. S., \& Rabins, P. V. (2008). Treatment decisions regarding hospitalization and surgery for nursing home residents with advanced dementia: the 
CareAD Study. International Psychogeriatrics, 20(2), 406-418. doi:

10.1017/S1041610207005807

Meyers, J. L., Moore, C., McGrory, A., Sparr, J., \& Ahern, M. (2004). Physician orders for lifesustaining treatment form: honoring end-of-life directives for nursing home residents. Journal of Gerontological Nursing, 30(9), 37-46.

Minino, A. M. (2011). Death in the United States, 2009. NCHS Data Brief(64), 1-8.

Mitchell, S. L., Berkowitz, R. E., Lawson, F. M., \& Lipsitz, L. A. (2000). A cross-national survey of tube-feeding decisions in cognitively impaired older persons. Journal of the American Geriatrics Society, 48(4), 391-397.

Mitchell, S. L., Kiely, D. K., \& Hamel, M. B. (2004). Dying with advanced dementia in the nursing home. Arcives of Internal Medicine, 164(3), 321-326. doi:

10.1001/archinte.164.3.321

Mitchell, S. L., Teno, J. M., Kiely, D. K., Shaffer, M. L., Jones, R. N., Prigerson, H. G., . . . Hamel, M. B. (2009). The clinical course of advanced dementia. The New England Journal of Medicine, 361(16), 1529-1538. doi: 10.1056/NEJMoa0902234

National POLST. (2012). Physician orders for life-sustaining treatment. Retrieved March 1, 2014, from http://www.polst.org/

Richardson, D. K., Fromme, E., Zive, D., Fu, R., \& Newgard, C. D. (2013). Concordance of Outof-Hospital and Emergency Department Cardiac Arrest Resuscitation With Documented End-of-Life Choices in Oregon. Annals of Emergency Medicine. doi:

10.1016/j.annemergmed.2013.09.004

Robinson, L., Dickinson, C., Bamford, C., Clark, A., Hughes, J., \& Exley, C. (2013). A qualitative study: professionals' experiences of advance care planning in dementia and 
palliative care, 'a good idea in theory but ...'. Palliative Medicine, 27(5), 401-408. doi: $10.1177 / 0269216312465651$

Sabatino, C. P., \& Karp, N. (2011). Improving advanced illness care: The evolution of state POLST programs. Washington, DC: AARP Public Policy Institute.

Silveira, M. J., Wiitala, W., \& Piette, J. (2014). Advance directive completion by elderly Americans: a decade of change. Journal of the American Geriatrics Society, 62(4), 706710. doi: 10.1111/jgs.12736

Teno, J. M., Gozalo, P., Mitchell, S. L., Bynum, J. P., Dosa, D., \& Mor, V. (2011). Terminal hospitalizations of nursing home residents: does facility increasing the rate of do not resuscitate orders reduce them? Journal of Pain and Symptom Management, 41(6), 10401047. doi: 10.1016/j.jpainsymman.2010.07.014

Teno, J. M., Gozalo, P. L., Bynum, J. P., Leland, N. E., Miller, S. C., Morden, N. E., ... Mor, V. (2013). Change in end-of-life care for Medicare beneficiaries: site of death, place of care, and health care transitions in 2000, 2005, and 2009. Journal of the American Medical Association, 309(5), 470-477. doi: 10.1001/jama.2012.207624

Tolle, S. W., Tilden, V. P., Nelson, C. A., \& Dunn, P. M. (1998). A prospective study of the efficacy of the physician order form for life-sustaining treatment. Journal of the American Geriatrics Society, 46(9), 1097-1102.

Triplett, P., Black, B. S., Phillips, H., Fahrendorf, S. R., Schwartz, J., Angelino, A. F., .. . Rabins, P. V. (2008). Content of advance directives for individuals with advanced dementia. Journal of aging and health, 20(5), 583-596.

Vandervoort, A., van den Block, L., van der Steen, J. T., Vander Stichele, R., Bilsen, J., \& Deliens, L. (2012). Advance directives and physicians' orders in nursing home residents 
with dementia in Flanders, Belgium: prevalence and associated outcomes. International Psychogeriatrics, 24(7), 1133-1143. doi: 10.1017/S1041610212000142

Vo, H., Pekmezaris, R., Guzik, H., Nouryan, C., Patel, C., Vij, B., . . Wolf-Klein, G. (2011). Knowledge and attitudes of health care workers regarding MOLST (Medical Orders for Life-Sustaining Treatment) implementation in long-term care facilities. Geriatric Nursing, 32(1), 58-62.

Wenger, N. S., Citko, J., O'Malley, K., Diamant, A., Lorenz, K., Gonzalez, V., \& Tarn, D. M. (2013). Implementation of Physician Orders for Life Sustaining Treatment in nursing homes in California: evaluation of a novel statewide dissemination mechanism. Journal of General Internal Medicine, 28(1), 51-57. doi: 10.1007/s11606-012-2178-2 


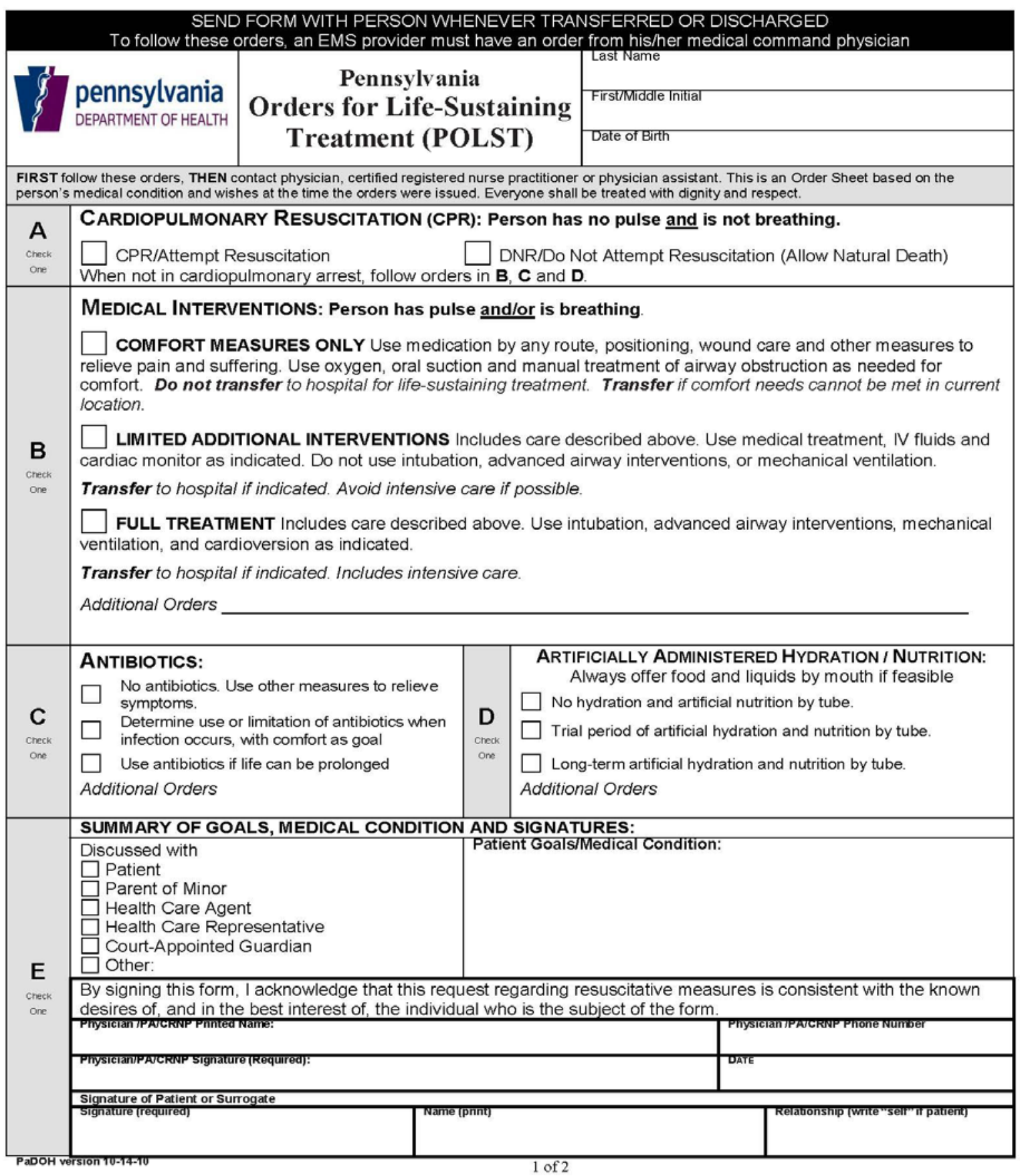

Figure 1. Example of the POLST form. Retrieved August 10, 2014, from

http://www.upmc.com/Services/AgingInstitute/partnerships-and-

collaborations/Documents/POLST-Form.pdf. No permission required 
Table 1

Priority of Surrogates

\begin{tabular}{|c|c|}
\hline \multicolumn{2}{|r|}{$\begin{array}{c}\text { Priority of Surrogates } \\
\text { (in absence of an appointed agent or guardian with health powers) } \\
\text { Examples: Florida, Pennsylvania and Washington State }\end{array}$} \\
\hline Florida & $\begin{array}{l}\text { - } \text { Spouse } \\
\text { - } \text { Adult child } \\
\text { - } \text { Parent } \\
\text { - } \text { Close adult Sibling } \\
\text { - } \text { Close friend } \\
\text { Licensed clinical social worker selected by bioethics committee, and if } \\
\text { decision is to forgo life-prolonging procedures, must be reviewed by } \\
\text { bioethics committee. }\end{array}$ \\
\hline Pennsylvania & $\begin{array}{l}\text { - } \text { Spouse } \\
\text { - } \text { Adult designated by others on this list, without objection by anyone on } \\
\text { - } \text { Adult child } \\
\text { - } \text { Parent } \\
\text { - Adult sibling } \\
\text { - } \text { Adult grandchild } \\
\text { Note: Individual may provide for a different order of priority by signed } \\
\text { writing. }\end{array}$ \\
\hline Washington & $\begin{array}{l}\text { - } \text { Spouse or registered domestic partner } \\
\text { - Adult children } \\
\text { - } \text { Parents } \\
\text { - Adult siblings }\end{array}$ \\
\hline
\end{tabular}

Note. Priority of surrogates. Adapted from

http://www.americanbar.org/content/dam/aba/administrative/law_aging/2014_default_surrogate_consent_ statutes.authcheckdam.pdf. Copyright 2014ㄷ by the American Bar Association. Reprinted with permission. This information or any or portion thereof may not be copied or disseminated in any form or by any means or stored in an electronic database or retrieval system without the express written consent of the American Bar Association. 
Table 2

Comparison of POLST and advance directives

\begin{tabular}{lll}
\hline Characteristics & POLST & Advance Directives \\
\hline Population & For the serious ill & All adults \\
Timeframe & Current care & Future care \\
Resulting form & Healthcare professionals & Patients \\
Healthcare agent or & Medical orders (POLST) & Advance directive \\
surrogate role & Can engage in discussion if & Cannot complete \\
Portability & patient lacks capacity & \\
& Provider responsibility & Patient/family \\
& & responsibility \\
Periodic review & Provider responsibility & Patient/family \\
& & responsibility
\end{tabular}

Note. Comparison of POLST and advance directives. Adapted from: Bomba, P. A., Kemp, M., Black, J.

S. POLST: An improvement over traditional advance directives. Cleve Clin J Med 2012; 79:457-464.

Copyright (C 2012 by the Cleveland Clinic Foundation. All rights reserved. Permission requested. 
Table 3

8-Step POLST Protocol

\section{Prepare for discussion}

- Review what is known about patient and family goals and values

- Understand the medical facts about the patient's medical condition and prognosis

- Review what is known about the patient's capacity to consent

- Retrieve and review completed Advance Directives and prior DNR documents

- Determine who key family members are, and (if the patient does not have the capacity), see if there is an identified health care agent, guardian or health care representative

- Find uninterrupted time for the discussion

\section{Begin with what the patient and family knows}

- Determine what the patient and family know regarding condition and prognosis

- Determine what is known about the patient's views and values in light of the medical condition

\section{Provide any new information about the patient's medical condition and values form} the medical team's perspective

- Provide information in small amounts, giving time for response

- Seek a common understanding; understand areas of agreement and disagreement

- Make recommendations based on clinical experience in light of patient's condition

4. Try to reconcile differences in terms of prognosis, goals, hopes and expectations

- Negotiate and try to reconcile differences; seek common ground; be creative

- Use conflict resolution when necessary

5. Respond empathetically

- Acknowledge

- Legitimize

- Explore (rather than prematurely reassuring)

- Empathize

- Reinforce commitment and nonabandonment

\section{Use POLST to guide choices and finalize patient/family wishes}

- Review the key elements with the patient and/or family

- Apply shared medical decision making

- Manage conflict resolution

\section{Complete and sign POLST}

- Get verbal or written consent from the patient or health care agent, guardian, health care representative

- Get written consent from the treating physician, and witnesses

- Document conversation

\section{Review and revise periodically}

Note. 8-Step POLST Protocol. This protocol was originally created for the MOLST Program of New

York State. More information can be found at www.compassionandsupport.org. Reprinted with

permission 